\title{
Editorial
}

\section{"The More Things Change, the More They Stay the Same": Research on Gang-Related Violence in the 21st Century-Introduction to Special Issue}

\author{
Matthew Valasik ${ }^{1, *}$ (I) and Shannon E. Reid ${ }^{2, *}$ \\ 1 Sociology Department, Louisiana State University, Baton Rouge, LA 70803, USA \\ 2 Criminology \& Criminal Justice, UNC Charlotte, 9201 University City Blvd, Charlotte, NC 28223, USA \\ * Correspondence: mvalasik@lsu.edu (M.V.); sreid33@uncc.edu (S.E.R.)
}

Citation: Valasik, Matthew, and Shannon E. Reid. 2021. “The More Things Change, the More They Stay the Same": Research on Gang-Related Violence in the 21st Century-Introduction to Special Issue. Social Sciences 10: 225 https://doi.org/10.3390/socsci 10060225

Received: 9 June 2021

Accepted: 9 June 2021

Published: 11 June 2021

Publisher's Note: MDPI stays neutral with regard to jurisdictional claims in published maps and institutional affiliations.

Copyright: (c) 2021 by the authors. Licensee MDPI, Basel, Switzerland. This article is an open access article distributed under the terms and conditions of the Creative Commons Attribution (CC BY) license (https:// creativecommons.org/licenses/by/ $4.0 /)$.
The goal of this Special Issue is to examine the diverse nature of gang-related violence in modern life by providing insights into the growing complexities to better direct public policy solutions in the 21st Century. Multiple perspectives and analytical techniques (e.g., quantitative, qualitative, or mixed-methods), across the United States and globally, are necessary to unpack the dynamic nature of gang-related violence today. Work on this Special Issue began just prior to COVID-19 upending the world and with it everyone's daily routines. We would like to thank first and foremost all of the contributors to this Special Issue. Despite the exceptionally challenging life circumstances, each article in this Special Issue highlights novel research methodologies to better understand gang violence and potential interventions to reduce it.

As the patterns of daily life changed with COVID-19 (i.e., quarantines, social distancing, etc.), researchers were frantic to understand how these changes to routine activities impacted all types of crime, from domestic violence (Nix and Richards 2021), to organized crime (De la Miyar et al. 2021), to cybercrime (Hawdon et al. 2020), and everything in between (Halford et al. 2020; Mohler et al. 2020; Rosenfeld and Lopez 2020). Studies generally show that crime patterns varied by the particular type of crime (e.g., theft, robbery, domestic violence, homicide, etc.) suggesting that the changes in the mobility patterns of offenders and victims directly contributes to these trends (Halford et al. 2020). Yet, emerging studies reveal that gang-related violence either remained stable (Brantingham et al. 2021) or increased (Kim and Phillips 2021) during the COVID-19 restrictions. It seems that even a global pandemic is unable to disrupt the prevalence of gang-related violence once it is entrenched in a community (see Valasik et al. 2017). That is, conflict, including the threat or fear of potential violence, remains the principal driver in sustaining gang life.

Dena Carson and Natalie Hipple (Carson and Hipple 2020), in their contribution to this Special Issue, "Comparing violent and non-violent gang incidents: An exploration of gang-related police incident reports," examine gang-related incident reports collected over four years (2015-2019) from the Indianapolis Metropolitan Police Department. They explore the reasons why incidents were attributed to gangs, and compare the characteristics of violent, drug, and non-violent gang-related incidents. Their analyses focus on examining the incident characteristics that influence a reporting officer's categorization of an incident as being gang-related and differentiating between violent, drug, and other non-violent crimes. Carson and Hipple find that non-violent crimes make up the bulk of gang-related incidents, followed by drug and then violent crimes. In fact, few incidents are labeled as gang-related by police and the prevalence is decreasing annually. Furthermore, violent crime incidents were more likely to be brought to the attention of the police through calls for service, with it being rare for police to observe violent gang-related activity during routine patrols. Overall, this study's findings are valuable to policy makers, criminal justice actors, and local agencies that work with gang members, since most $(62 \%)$ of the 
gang-related incident reports involve non-violent offenses, requiring programs and policies to address more than just violence.

Matthew Valasik and Shannon Reid (Valasik and Reid 2021), in "East Side Story: Disaggregating Gang Homicides in East Los Angeles", argue that gang-related homicides are not monolithic but have significantly distinct characteristics. Their study discusses the variation in the circumstances, motives, setting, participant characteristics, and rivalry relationship present in gang-related homicides to see how they vary from one another. Using Latent Class Analysis (LCA) to classify cases into mutually exclusive types (classes), Valasik and Reid examine gang-related homicides in the LAPD's Hollenbeck Community Policing Area between 1990 and 2012. The results reveal five mutually exclusive classes of gang-related violence that are distinct from each other. Valasik and Reid's study provides evidence that patterned variation exists in gang-related homicides, arguing that disaggregation should be a regularly employed tool to understand the unique differences between classes of gang-related homicides for policy, law enforcement response, and research.

Civil gang injunctions (CGIs) have been a crime control strategy used to target the most violent street gangs by imposing behavioral restrictions on enjoined gang members (e.g., prohibitions against congregating in public) within a designated area (e.g., a gang's claimed turf) with the hopes of deterring gang violence. The City of Los Angeles, in particular, has adopted this tactic. Gisela Bichler, Alexis Norris, and Citlalik Ibarra (Bichler et al. 2020), in "Evolving Patterns of Aggression: Investigating the Structure of Gang Violence during the Era of Civil Gang Injunctions", examine the four social networks generated from violent incidents occurring between the years 1998 and 2013 involving enjoined gang members. The novel data were generated by linking defendants and victims named in 963 prosecutions involving street gangs enjoined with a CGI. Bichler and colleague's goal is ascertaining whether the substantive shifts in the structure of violence correspond with phases of CGI adoption in Los Angeles. Exploring the structure of conflict through a triad census, their findings reveal that across time periods, a substantial number of simple structures reflect a domino pattern of aggression. That is, one group attacks another, who then attacks a third group. Bichler and colleagues suggest that this structure of violence indicates that not all gangs are equal, with some gangs being unable to retaliate and instead prey upon weaker groups. Additionally, there was a substantial change after CGIs were introduced, with many simple structures of violence shifting to more complex patterns. The findings reveal that enjoined gangs were more likely to attack other enjoined gangs, and excessively aggressive gangs were less likely to be victimized. This study provides support for targeted enforcement strategies being able to facilitate change in gang violence; however, as more and more injunctions were enacted the nature of gang conflict became more complex. As such, the disruption of future gang violence may become more challenging in the long-term.

Alice Airola and Martin Bouchard's (Airola and Bouchard 2020) contribution, "The Social Network Consequences of a Gang Murder Blowout," also utilizes social network analysis (SNA), but focuses on a sole gang, Red Scorpion, whose members were involved in the Surrey Six Murder, one of the deadliest gang-related homicides in Canada. By using SNA, Airola and Bouchard are able to examine the network consequences for the organization and its members resulting from this gang-related homicide. The following three types of ties are focused on in the network: trust ties (strong), business ties (weak), and conflict ties (negative). Airola and Bouchard compare the different social ties and the level of control during the conspiracy phase and the post-murder phase, revealing that the fragmentation and network size increased post-murder, whereas the Red Scorpion's network density and centralization decreased. Similar to the terrorist group, Toronto 18, Red Scorpion's network showed signs of fragmentation after crisis as the role of the leader was diminished after the murder. In addition, following the murder, the proportion of trust ties increased and so did the number of positive and balanced cliques, which, as Airola and Bouchard argue, suggests that such strong ties are effective at maintaining the information flow and control of a group when facing a crisis. This unique case study 
provides glimpses into how the composition of street gangs are not static structures but change in response to stimuli, for instance a law enforcement murder investigation and prosecution, and should be kept in mind when such groups are targeted with intervention and/or suppression strategies.

Marta Urbanik and Robby Roks' (Urbanik and Roks 2021) article, "Making Sense of Murder: The Reality versus the Realness of Gang Homicides in Two Contexts," employs a multi-site (Canada and the Netherlands) ethnographic approach to illuminate how gang members experience their associates' murder(s). Particular attention focuses on how gang members make sense of and respond to the fatalities of their peers. Gang members in both Canada and the Netherlands made sense of and navigated a fellow member's murder(s) by conducting pseudo-homicide investigations, being hypervigilant, and attributing blame to the victim. They discussed potential suspects and motives, reviewed eyewitness reports, and analyzed crime scene photos published by the local media. Urbanik and Roks find that following a gang-related murder, fellow gang members are more likely to carry a weapon, pay extra attention to strangers, minimize their presence outdoors, and share suspicions about who may be responsible. In the Netherlands, a gang member's murder planted doubts about the function and necessity of defending a gang's claimed turf. While in Canada, many gang members became desensitized and accustomed to the routineness of fellow gang members being murdered, with these events breeding distrust between group members. Urbanik and Roks' approach is eye-opening, providing an alternative data source that is not police generated and is better able to unpack the micro processes associated with gang-related homicides.

In another multi-site study (two east coast cities in the United States), Caterina Roman, Meagan Cahill, and Lauren R. Mayes' (Roman et al. 2021) article, "Changes in Personal Social Networks across Individuals Leaving Their Street Gang: Just What Are Youth Leaving Behind?", analyzes the changes in a gang member's personal network composition as it is associated with changes in a gang member's membership stage. Using novel survey data, Roman and colleagues observe notable differences between individuals who reported leaving their gang and fully disengaging from their gang associates, and those who report leaving but still interact with their gang friends. The results indicate that the individuals who fully disengaged from their street gang acquired more prosocial relationships and reduced some of their criminal behavior. For those who left their gang but still interact with fellow gang members, however, there were limited changes for both criminal behavior and network composition over time. Roman and colleagues contend that a complete withdrawal from interaction with old gang members is likely followed by large changes in the composition of social networks, particularly if prosocial relationships can be established. This study supports the notion that crime desistance is more clearly tied to full disengagement than simply de-identification as a gang member. These findings suggest that gang intervention programs that use street outreach workers may be an effective strategy to reduce violence and put high-risk individuals and gang members on prosocial paths.

A gang intervention that has consistently been shown as an effective strategy at reducing gang-related violence is focused deterrence. Involving a mixture of strong enforcement messages from law enforcement officials that stress the costs and consequences of gun violence combined with the promise of additional social support and resources, focused deterrence has been employed across many jurisdictions over the last thirty years. Focused deterrence was implemented in Philadelphia between 2013 and 2016, resulting in a significant decrease in shootings; however, the effect on targeted gangs was not universal, with some showing no change or an increase in gun-related activity. Jordan Hyatt, James Densley, and Caterina Roman (Hyatt et al. 2021), in "Social Media and the Variable Impact of Violence Reduction Interventions: Re-Examining Focused Deterrence in Philadelphia," study the extent to which social media may explain this differential. Specifically, does social media's use as a venue for communication diminish the robustness of a focused deterrence message, which focuses on reinforcing a sense of collective accountability. Employing data 
on group-level social media usage and content, Hyatt and colleagues reveal that all street gangs have an online presence and promoted violence in almost one-third of their postings. Furthermore, gangs with more shootings are younger with slightly larger memberships, suggesting that these groups are likely to have a higher overall social media usage score and a larger, more visible footprint on the internet. While the social media posts that are considered to be an immediate threat did not correlate with an increase in shootings during a focused deterrence period, instead the broader pattern of online engagement was associated with an increased level of risk. These findings support the link between the online activity of gang members and violence on the streets, especially shootings. As such, this study reinforces the need to not ignore social media when developing harm-prevention interventions, including focused deterrence, for gang-involved individuals.

A novel approach to street gang intervention is the Good Lives Model (GLM), a strengths-based framework for offender rehabilitation. Mallion and Wood (2020), in "Street Gang Intervention: Review and Good Lives Extension," maintain that this public health approach to gang membership assumes that criminal behavior occurs when individuals are unable to attain their goals through prosocial means and will instead attempt to achieve these goals through any means necessary, including antisocial behaviors. For gang members in particular, gangs may provide a sense of protection and support, yet there is also an increased risk of violent victimization and mental illness. Mallion and Wood highlight that GLM interventions aim to develop an individual's internal (i.e., skills and values) and external capacities (i.e., resources, support, and opportunities). Current prevention and intervention strategies are limited in their effectiveness, as the benefits of belonging to a gang (e.g., protection, social and emotional support, sense of identity) extend beyond the normal proceeds of crime (i.e., financial or material gain) and are generally not adequately targeted in traditional interventions. GLM-consistent interventions provide a relatively new framework that may increase client engagement and motivation to change.

Lastly, "Exploring the Influence of Drug Trafficking Gangs on Overdose Deaths in the Largest Narcotics Market in the Eastern United States" by Nicole Johnson, Caterina Roman, Alyssa Mendlein, Courtney Harding, Melissa Francis, and Laura Hendrick (Johnson et al. 2020) investigates whether deaths from accidental drug overdose are clustered around street corners controlled by drug trafficking gangs in a large neighborhood in Philadelphia, Pennsylvania. Using a concentration metric, the Rare Event Concentration Coefficient, to assess clustering of overdose deaths annually between 2015 and 2019, the study reveals that overdose deaths became less clustered over time. Johnson and colleagues find several socio-structural factors that are associated with a higher rate of overdose deaths, including concentrated disadvantage and physical environmental factors (e.g., dilapidated or deteriorated housing). Additionally, both the gang corner status and the proximity to a street gang were significantly related to the rate of overdose incidents on each street corner. The findings suggest that programs seeking to address overdose deaths should be both mobile and be specifically targeted to risky places. Implications of this study highlight the need for efforts to strategically coordinate law enforcement and social service provisions and reduce deteriorated housing stock would be the most effective at reducing drugs, other crime, and overdoses.

The contributions included in this Special Issue highlight the complex nature of gang-related violence in the 21st Century. As much as policy makers, the media, and even scholars like to simplify gang-related violence, all of the above studies highlight the nuance and variation that exists. Furthermore, tried and true approaches (e.g., homicide disaggregation) and interventions (e.g., focused deterrence, CGIs) should be reviewed and brought into the 21st Century to address gang-related violence effectively and appropriately in the present day. Through the use of novel data and methods, the studies presented in this Special Issue reinforce this need. Gang-related violence is a persistent beast, difficult to dislodge from communities and, as society begins to reopen from the COVID-19 pandemic and return to our daily routines, it will be there waiting for us to reemerge. 
Author Contributions: Conceptualization, M.V. and S.E.R.; writing-original draft preparation, M.V.; writing-review and editing, M.V. and S.E.R. All authors have read and agreed to the published version of the manuscript.

Conflicts of Interest: The authors declare no conflict of interest.

\section{References}

Airola, Alice, and Martin Bouchard. 2020. The Social Network Consequences of a Gang Murder Blowout. Social Sciences 9: 204. [CrossRef]

Bichler, Gisela, Alexis Norris, and Citlalik Ibarra. 2020. Evolving Patterns of Aggression: Investigating the Structure of Gang Violence during the Era of Civil Gang Injunctions. Social Sciences 9: 203. [CrossRef]

Brantingham, P. Jeffrey, George E. Tita, and George Mohler. 2021. Gang-related crime in Los Angeles remained stable following COVID-19 social distancing orders. Criminology \& Public Policy. [CrossRef]

Carson, Dena, and Natalie K. Hipple. 2020. Comparing violent and non-violent gang incidents: An exploration of gang-related police incident reports. Social Sciences 9: 199. [CrossRef]

De la Miyar, Jose Roberto Balmori, Lauren Hoehn-Velasco, and Adan Silverio-Murillo. 2021. Druglords don't stay at home: COVID-19 pandemic and crime patterns in Mexico City. Journal of Criminal Justice 72: 101745. [CrossRef] [PubMed]

Halford, Eric, Anthony Dixon, Graham Farrell, Nicolas Malleson, and Nick Tilley. 2020. Crime and coronavirus: Social distancing, lockdown, and the mobility elasticity of crime. Crime Science 9: 1-12. [CrossRef] [PubMed]

Hawdon, James, Katalin Parti, and Thomas E. Dearden. 2020. Cybercrime in America amid COVID-19: The initial results from a natural experiment. American Journal of Criminal Justice 45: 546-62. [CrossRef] [PubMed]

Hyatt, Jordan M., James A. Densley, and Caterina G. Roman. 2021. Social Media and the Variable Impact of Violence Reduction Interventions: Re-Examining Focused Deterrence in Philadelphia. Social Sciences 10: 147. [CrossRef]

Johnson, Nicole J., Caterina G. Roman, Alyssa K. Mendlein, Courtney Harding, Melissa Francis, and Laura Hendrick. 2020. Exploring the Influence of Drug Trafficking Gangs on Overdose Deaths in the Largest Narcotics Market in the Eastern United States. Social Sciences 9: 202. [CrossRef]

Kim, Dae-Young, and Scott W. Phillips. 2021. When COVID-19 and guns meet: A rise in shootings. Journal of Criminal Justice 73: 101783. [CrossRef] [PubMed]

Mallion, Jaimee, and Jane Wood. 2020. Street Gang Intervention: Review and Good Lives Extension. Social Sciences 9: 160. [CrossRef]

Mohler, George, Andrea L. Bertozzi, Jeremy Carter, Martin B. Short, Daniel Sledge, George E. Tita, Craig D. Uchida, and P. Jeffrey Brantingham. 2020. Impact of social distancing during COVID-19 pandemic on crime in Los Angeles and Indianapolis. Journal of Criminal Justice 68: 101692. [CrossRef] [PubMed]

Nix, Justin, and Tara N. Richards. 2021. The immediate and long-term effects of COVID-19 stay-at-home orders on domestic violence calls for service across six US jurisdictions. Police Practice and Research 22: 1443-51. [CrossRef]

Roman, Caterina G., Meagan Cahill, and Lauren R. Mayes. 2021. Changes in Personal Social Networks across Individuals Leaving Their Street Gang: Just What Are Youth Leaving Behind? Social Sciences 10: 39. [CrossRef]

Rosenfeld, Richard, and Ernesto Lopez. 2020. Pandemic, Social Unrest, and Crime in US Cities. Washington, DC: Council on Criminal Justice.

Urbanik, Marta-Marika, and Robert A. Roks. 2021. Making Sense of Murder: The Reality versus the Realness of Gang Homicides in Two Contexts. Social Sciences 10: 17. [CrossRef]

Valasik, Matthew, and Shannon E. Reid. 2021. East Side Story: Disaggregating Gang Homicides in East Los Angeles. Social Sciences 10: 48. [CrossRef]

Valasik, Matthew, Michael S. Barton, Shannon E. Reid, and George E. Tita. 2017. Barriocide: Investigating the temporal and spatial influence of neighborhood structural characteristics on gang and non-gang homicides in East Los Angeles. Homicide Studies 21: 287-311. [CrossRef] 